\title{
COMPARAÇÃO ENTRE O TEOR LIPÍDICO DO LODO GERADO POR Anabaena flos-aquae e Chlorella vulgaris NOS PROCESSOS DE TRATAMENTO DE ÁGUA
}

\author{
L. O. R. MORETI ${ }^{1 *}$, F. P. CAMACHO ${ }^{1}$, M. O. SILVA ${ }^{1}$, L. NISHI ${ }^{1}$, M. F. SILVA ${ }^{1}$, R. \\ BERGAMASCO ${ }^{1}$
}

${ }^{1}$ Universidade Estadual de Maringá, Departamento de Engenharia Química *e-mail: li.moreti@hotmail.com

\begin{abstract}
RESUMO
O presente trabalho teve como objetivo avaliar a eficiência dos processos de coagulação/floculação/flotação por ar dissolvido (C/F/FAD) utilizando pó integral de sementes de Moringa oleifera Lam, como coagulante natural para remoção das células Anabaena flos-aquae e Chlorella vulgaris com posterior caracterização lipídica do lodo gerado. Para a realização dos experimentos preparou-se uma "água sintética", a partir do meio de cultura ASM-1 contendo células de A. flos-aquae na concentração de $10^{4}$ células. $\mathrm{mL}^{-1}$, simulando uma floração e para o cultivo de $C$. vulgaris foi utilizado o meio de cultura BG-11, na concentração de $10^{-6}$ células. $\mathrm{mL}^{-1}$. Para os ensaios de C/F/FAD foi utilizado o equipamento "flotest" e para avaliar o perfil de ácidos graxos foi utilizado um cromatógrafo a gás. A dosagem ótima do coagulante testado foi diferente para ambas as algas, sendo obtida 0,1 g. $\mathrm{L}^{-1}$ para $A$. flos-aquae, atingindo remoção de $96,4 \%$ de clorofila-a e 0,4 g.. $\mathrm{L}^{-1}$ para $C$. vulgaris, atingindo remoção de 90,5\%. Em relação ao perfil de ácidos graxos presentes pode-se observar que em ambas as espécies houve um aumento na porcentagem do ácido oleico após o tratamento com Moringa oleifera, atingindo valores de $61,7 \%$ para A. flosaquae e $69,5 \%$ para $C$. vulgaris.
\end{abstract}

\section{INTRODUÇÃO}

Vários coagulantes naturais tem sido estudados para purificação de água, recentemente a Moringa oleifera Lam vem se destacando, pois apresenta boa remoção de cor e turbidez, além de promover grandes remoções de bactérias, acima de $90 \%$ (NKURUNZIZA et al., 2009; NWAIWU e LINGMU, 2011). Atualmente há poucos estudos sobre a aplicação desse coagulante em águas eutrofizadas, porém em alguns trabalhos pode-se observar uma excelente eficiência de remoção de células de microalgas (NISHI, et al., 2011; CAMACHO, et al., 2013).

A flotação por ar dissolvido tem sido considerada uma alternativa viável à etapa de sedimentação quando aplicada ao tratamento de águas com presença de microalgas, já que este processo é capaz de remover células intactas, quando comparada ao processo de sedimentação, além de diminuir o tempo de contato entre o lodo gerado e a água em 
tratamento. A remoção do resíduo gerado é realizada por equipamentos mecânicos que são instalados sobre a água e possuem manuntenção mais fácil do que os raspadores de fundo de decantadores (TEXEIRA et al., 2007; AMARAL et al. 2013)

A destinação adequada do lodo gerado por estações de tratamento de água é essencial, visto que este de acordo com a ABNT NBR 10004 (2004) é considerado um resíduo sólido, que se lançado sem devido tratamento nos cursos d'água, pode causar efeitos diretos ao ambiente aquático, prejudicando a fauna e a flora do corpo receptor.

A despreocupação para com o resíduo gerado, causam impactos como, aumento na quantidade de sólidos nos corpos d'água, assoreamento dos corpos d'água, aumento da cor, turbidez e concentração de alumínio na água, redução do $\mathrm{pH}$ da água, liberação de odores, redução da quantidade de oxigênio dissolvido no corpo d'água, toxicidade crônica nos organismos aquáticos e impacto visual.

No entanto, este estudo busca alternativas ambientalmente viáveis de reaproveitamento da biomassa de algas presente no lodo gerado por estações de tratamento de água, como por exemplo, avaliar o teor lipídico produzido por essas algas a fim de destiná-los a uma futura produção de biodiesel.

Desta forma, este trabalho tem por objetivo avaliar a eficiência de remoção de clorofila-a de duas espécies de microalgas, utilizando como coagulante natural sementes trituradas de Moringa oleifera com posterior caracterização do perfil lipídico.

\section{MATERIAL E MÉTODO}

\subsection{Cultivo}

As culturas foram realizadas a partir de inóculo precursor das culturas puras de
Anabaena flos-aquae e Chlorella vulgaris fornecidas pelo laboratório de Cianobactérias, Departamento de Ciências Biológicas, USP Piracicaba/SP. A inoculação das culturas foram realizadas quinzenalmente, seguindo a proporção de inóculo : meio (1:9), até atingir a concentração na ordem de $10^{4}$ células. $\mathrm{mL}^{-1}$ para A. flos-aquae e $10^{6}$ células. $\mathrm{mL}^{-1}$ para $C$. vulgaris. $\mathrm{O}$ cultivo da espécie de cianobactéria foi mantido no meio ASM-1 e o de alga verde no meio BG-11, autoclavados, preparados com água deionizada, sob condições de máxima assepsia, temperatura controlada em torno de $25^{\circ} \mathrm{C}$, sob lâmpadas fluorescentes (Philips TLT $20 \mathrm{~W} / 75 \mathrm{~S}$ cool) com foto-período de 12 horas (claro/escuro).

\subsection{Processo de coagulação/ floculação/ flotação por ar dissolvido}

As sementes de Moringa oleifera foram cedidas pela Universidade Federal de Sergipe.

Para a obtenção do coagulante em pó de MO, as sementes foram descascadas e trituradas em liquidificador e secas em estufa até peso constante.

As dosagens do coagulante natural Moringa oleifera Lam utilizadas nos ensaios foram adaptadas segundo dados citados na literatura, sendo de 0,$05 ; 0,1 ; 0,2 ; 0,4 ; 0,5$; 0,6; 0,8 e 1,0 g.L - $^{-1}$ (TEIXEIRA et al., 2012), a fim de avaliar a concentração ótima do coagulante para cada espécie.

Os ensaios de coagulação/floculação/flotação por ar dissolvido foram conduzidos no equipamento "flotest" Nova Ética.

As condições experimentais foram: gradiente de mistura rápida (GMR), tempo de mistura rápida (TMR), gradiente de mistura lenta (GML), tempo de mistura lenta (TML), pressão de saturação ( $\left.\mathrm{P}_{\text {sat }}\right)$, tempo de saturação $\left(\mathrm{T}_{\text {sat }}\right)$, velocidade de flotação $\left(\mathrm{V}_{\text {flot }}\right)$ e taxa de recirculação $(\mathrm{R})$, conforme a Tabela 1 . 
Tabela 1 - Condições de operação para $\mathrm{C} / \mathrm{F} / \mathrm{FAD}$

\begin{tabular}{c|c}
\hline Parâmetros & Valores \\
\hline GMR & $850 \mathrm{~s}^{-1}$ \\
TMR & $20 \mathrm{~s}$ \\
GML & $15 \mathrm{~s}^{-1}$ \\
TML & $20 \mathrm{~min}$ \\
$\mathrm{P}_{\text {sat }}$ & $600 \mathrm{KPa}$ \\
$\mathrm{T}_{\text {sat }}$ & $4 \mathrm{~min}$ \\
$\mathrm{R}$ & $30 \%$ \\
$\mathrm{~V}_{\text {flot }}$ & $10 \mathrm{~cm} \cdot \mathrm{min}^{-1}$ \\
\hline
\end{tabular}

Fonte (autor)

Análises de cor, turbidez, clorofila-a e compostos com absorção em $\mathrm{UV}_{254 \mathrm{~nm}}$ foram realizados antes e depois dos ensaios para avaliar a eficiência do processo através das porcentagens de remoção.

A caracterização da água sintética foi realizada por meio dos parâmetros: cor aparente e compostos com absorção em $\mathrm{UV}_{254 \mathrm{~nm}}$ (espectrofotômetro DR $5000 \mathrm{Hach}$ ), turbidez (turbidímetro 2100P Hach), $\mathrm{pH}$ (pHmetro Thermo-Scientific VSTAR92 Orion Versastar) e clorofila-a (GOLTERMAN et al.,1978).

\subsection{Análise estatística}

Os ensaios foram realizados em duplicatas e os resultados obtidos nos testes de $\mathrm{C} / \mathrm{F} / \mathrm{FAD}$ foram avaliados pela análise de variância (ANOVA) e teste de comparação de médias, teste Tukey, com 95\% de nível de confiança, através do programa Statsoft STATISTICA versão 8.0. Assim, pode-se verificar as diferenças das eficiências de remoção dos parâmetros (turbidez, cor, clorofila-a e $\left.U_{254 n m}\right)$ e avaliar a concentração ótima de Moringa oleifera utilizada no processo de C/F/FAD.

\subsection{Análise do perfil lipídico das microalgas}

Para a análise do perfil de ácidos graxos, em primeiro lugar, a extração do óleo da biomassa algal foi feita pelo método de Blight e Dyer (1959). Para a conversão de ésteres metílicos, a esterificação dos lípideos foi desenvolvida pela metodologia descrita por Hartman e Lago (1973).

Os ácidos graxos foram analisados por cromatografia gasosa CP- 3380 (Varian, EUA), equipado com detector de ionização de chama e uma coluna capilar de sílica fundida Selecione FAME (CP- 7420, Varian), com comprimento de $100 \mathrm{~m}$ (ID 0,25 milímetros e 0,25 filme micrômetro).

A identificação dos ácidos graxos foram realizadas utilizando o software Varian, por comparação dos tempos de retenção com padrões de Sigma (EUA) e as áreas de pico medições foi determinado pelo software de versão Clareza Lite 2.4.1.91.

\section{RESULTADOS E DISCUSSÕES}

A Tabela 2 apresenta a caracterização das águas sintéticas.

Tabela 2 - Caracterização das águas sintéticas

\begin{tabular}{lcc}
\hline & \multicolumn{2}{c}{ Espécies } \\
\hline Parâmetros & $\begin{array}{c}\text { Chlorella } \\
\text { vulgaris }\end{array}$ & $\begin{array}{c}\text { Anabaena } \\
\text { flos-aquae }\end{array}$ \\
\hline Concentração & $1 \times 10^{6}$ & $1 \times 10^{4}$ \\
células (céls.mL $\left.\mathbf{- 1}^{-1}\right)$ & 549 & 224 \\
Cor (uH) & $30 \pm 4$ & $30 \pm 0,5$ \\
Turbidez (NTU) & 0,206 & 0,170 \\
UV $_{\text {254nm }}$ & 444,19 & 149,5 \\
Clorofila-a & & \\
\hline
\end{tabular}

Fonte (autor)

\subsection{Processos de C/F/FAD}

Avaliando-se os resultados obtidos (Figura 1), pode-se observar as porcentagens de remoções dos parâmetros cor, turbidez, clorofila-a e compostos com absorção em $\mathrm{UV}_{254 \mathrm{~nm}}$, indicando a dosagem ótima do coagulante utilizado. 
Figura 1 - Remoção de Cor, Turbidez, Compostos com absorção em UV $\mathrm{UV}_{254 \mathrm{~nm}}$ e Clorofilaa em relação à dosagem do pó de Moringa oleifera para A. flos-aquae.

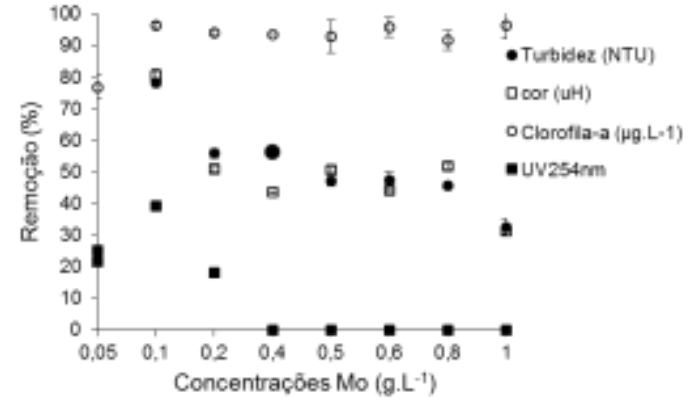

Fonte (autor)

Os resultados apontam que o pó da semente da Moringa adicionada diretamente às suspensões celulares apresenta-se eficiente na remoção de células, cor e turbidez, chegando atingir remoções de até 96,4, 80,5 e $78,1 \%$, respectivamente para a dosagem de 0.1 g. $\mathrm{L}^{-1}$ de pó de Moringa, a qual após análise estatística foi considerada ideal para este estudo.

Com relação a remoção de $U_{254 n m}$ nota-se que a MO não obteve resultados muito satisfatórios, atingindo um máximo de $39,1 \%$ de remoção na dosagem de 0,1 g.L $\mathrm{L}^{-1}$. Houve uma queda na eficiência de remoção conforme aumentou-se a dosagem de Moringa. Este resultado pode estar atribuído pelo fato da Moringa ser um coagulante orgânico, composta basicamente de proteínas, lipídeos e carboidratos, responsáveis pelo residual orgânico na água tratada.

Avaliou-se também a dosagem ótima de Moringa para a espécie de $C$. vulgaris, que é uma alga unicelular, com a finalidade de verificar se a morfologia diferente das algas interfere na eficiência de remoção dos parâmetros. Desta forma, pode-se observar que a dosagem ótima do coagulante Moringa foi diferente entre as espécies. Para $C$. vulgaris, a dosagem ótima de Moringa foi de 0,4 g.L $L^{-1}$, verificado através das porcentagens de remoções dos parâmetros cor $(78,34 \%)$, turbidez (70\%), clorofila-a $(90,5 \%)$ e compostos com absorção em $\mathrm{UV}_{254 \mathrm{~nm}}(16 \%)$ ilustrados pela Figura 2.

Figura 2 - Remoção de Cor, Turbidez, Compostos com absorção em UV $\mathrm{UV}_{254 \mathrm{~nm}}$ e Clorofilaa em relação à dosagem do pó de Moringa oleifera para C. vulgaris.

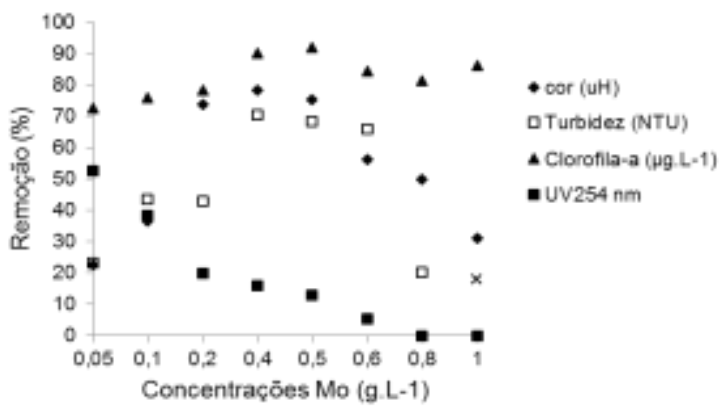

Fonte (autor)

Assim, observou-se que os processos de C/F/FAD utilizados juntamente com Moringa oleifera como coagulante natural, teve uma excelente eficiência para ambas as espécies testadas, conforme mostra a Figura 3.

Figura 3 - Indicação da formação da manta de material flotado de A. flos-aquae.

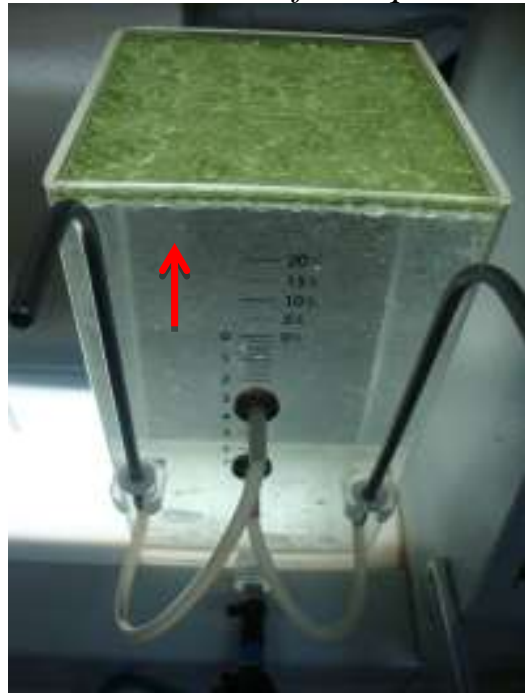

Fonte (autor)

A injeção de ar no sistema de FAD tem como objetivo, promover a formação de uma espécie de "rede" que permite a ascensão dos flocos para a superfície. Durante a realização 
dos ensaios experimentais, verificou-se uma estabilidade neste "suporte", tendo-se, a presença de bolhas visíveis na manta de material flotado.

\subsection{Determinação do perfil de ácidos graxos do lodo gerado}

Primeiramente, foram identificados os ésteres de ácidos graxos das microalgas sem o tratamento com Moringa oleifera. Pode-se verificar que os ácidos graxos saturados corresponderam a 40,4\% da composição de $C$. vulgaris e $35,85 \%$ de A. flos aquae enquanto que os insaturados apresentaram valores de $39,58 \%$ e $40,1 \%$ respectivamente. Dentre os ácidos que apresentaram maiores valores em C. vulgaris destacam-se o C20:0 (ácido araquídico) com 21,15\%, C18:1n9 (ácido oleico) com 18,85\% seguidos do C16:0 (ácido palmítico) e do C18:2n6 (ácido linoléico) com cerca de $15 \%$ cada. Já para A. flos aquae as maiores porcentagens deve-se primeiramente ao C16:0 (ácido palmítico) com 30,55\%, em seguida o C18:2n6 (ácido linoleico) apresentou $17 \%$ e, por fim, o C18:1n9 (ácido oleico) apresentou 7,4\% da sua composição, demonstrados na Tabela 3.

Tabela 3 - Perfil cromatográfico das microalgas sem tratamento com Moringa oleifera

\begin{tabular}{lrcc}
\hline & \multicolumn{3}{c}{$\begin{array}{c}\text { \% da média de Ácidos Graxos } \\
\text { presente nas microalgas sem } \\
\text { tratamento }\end{array}$} \\
\cline { 3 - 4 } Ácidos graxos & & $\begin{array}{c}\text { Chlorella } \\
\text { vulgaris }\end{array}$ & $\begin{array}{c}\text { Anabaena flos- } \\
\text { aquae }\end{array}$ \\
\hline Saturados & $\mathbf{1 0 : 0 0}$ & 0,2 & 0,25 \\
& $\mathbf{1 2 : 0 0}$ & 0,35 & 0,35 \\
& $\mathbf{1 4 : 0 0}$ & 0,55 & 0,6 \\
& $\mathbf{1 5 : 0 0}$ & 0,55 & - \\
$\mathbf{1 6 : 0 0}$ & 15,35 & 30,55 \\
$\mathbf{1 7 : 0 0}$ & 0,2 & - \\
$\mathbf{1 8 : 0 0}$ & 1,1 & 2,3 \\
$\mathbf{2 0 : 0 0}$ & 21,15 & 0,1 \\
$\mathbf{2 1 : 0 0}$ & 0,2 & 0,25 \\
$\mathbf{2 2 : 0 0}$ & 0,6 & 1,45 \\
$\mathbf{2 4 : 0}$ & 0,15 & -
\end{tabular}

\begin{tabular}{lccc} 
Subtotal & & 40,4 & 35,85 \\
\hline Monoinsaturados & $\mathbf{1 6 : 0 1}$ & 0,8 & 1,2 \\
& $\mathbf{2 0 : 0 1}$ & 1,45 & 2,15 \\
& $\mathbf{2 4 : 1}$ & 0,3 & 0,55 \\
Subtotal & & 2,55 & 3,9 \\
\hline poli-insaturados & $\mathbf{1 5 : 1 n 5}$ & 1 & 0,95 \\
& $\mathbf{1 8 : 1 n 9}$ & 18,85 & 7,4 \\
& $\mathbf{1 8 : 2 n 6}$ & 15,13 & 17 \\
& $\mathbf{1 8 : 3 n 6}$ & 0,95 & 2,35 \\
& $\mathbf{2 0 : 3 n 3}$ & 0,8 & 1,9 \\
& $\mathbf{2 0 : 3 n 6}$ & 0,3 & - \\
& $\mathbf{2 0 : 5 n 3}$ & 0,2 & 4 \\
Subtotal & $\mathbf{2 2 : 0 2}$ & - & 2,6 \\
\hline Não identificados & & 37,23 & 36,2 \\
\hline & & 19,8 & 23,95 \\
Lipídeos totais & total & 100 & 100 \\
\hline
\end{tabular}

Fonte (autor)

A espécie Chlorela vulgaris apresentou teor lipídico de $5 \%$ do seu peso seco, valor superior à espécie de cianobactéria estudada (Anabaena flos-aquae), que foi de $3,05 \%$, porém este resultado pode ser revertido, visto que $\mathrm{o}$ meio $\mathrm{e}$ as condições de cultivo otimizados podem potencializar as produções de lipídeo pela alga, como luz (FERNANDEZ et al., 2000), concentração de dióxido de carbono (ARAUJO e GARCIA, 2005), temperatura (RENAUD et al., 2002; COLLA et al., 2004), concentração da fonte de nitrogênio (COLLA et al., 2004), entre outros nutrientes. $\mathrm{O}$ valor obtido para $C$. vulgaris vai de encontro com os resultados obtidos por Radman e Costa (2008), que apresentaram concentrações de aproximadamente $5,97 \%$ de teor lipídico para a mesma alga e sob as mesmas condições de cultivo e meio BG-11.

Embora haja poucos trabalhos relatando o perfil lipídico de Anabaena flos- aquae, os resultados obtidos neste estudo apresentam valores próximos aos apresentados por Nichols e Wood (1967) em que apresentam C16:0 (39,5\%), C16:1 (5,5\%), C18:1 (5,2\%) C18:2 (36,5\%) como os principais ácidos 
graxos pertencentes da maioria da composição desta alga.

Após tratamento com as dosagens ótimas de Moringa oleifera fez-se novamente a análise e observou-se que resultados apresentados na Tabela 4, demonstram que após o tratamento com as dosagens ótimas de coagulante, as porcentagens de lipídeos totais de cada amostra sofreu um aumento, visto pelos valores de $16,4 \%$ dos lipídeos totais para C. vulgaris e 6,2\% para A. flos-aquae. Este aumento provavelmente está relacionado ao residual de coagulante Moringa oleifera no lodo, pois segundo a caracterização físicoquímica realizada nas sementes de Moringa oleifera vindas de Aracaju - SE, estas apesentam aproximadamente $37 \%$ de lipídeos na sua composição (SILVA, 2013). Sendo assim, a maioria dos ácidos graxos presentes nas amostras de ambas as espécies de microalgas foram dos ácidos graxos insaturados.

Tabela 4 - Perfil cormatográfico das microalgas após tratamento com Moringa oleifera

\begin{tabular}{lrcc}
\hline & & $\begin{array}{c}\text { \% da média de Acidos Graxos } \\
\text { presente nas microalgas tratadas } \\
\text { com Moringa }\end{array}$ \\
\cline { 3 - 4 } Ácidos graxos & & $\begin{array}{c}\text { Chlorella } \\
\text { vulgaris }\end{array}$ & $\begin{array}{c}\text { Anabaena flos- } \\
\text { aquae }\end{array}$ \\
\hline Saturados & $\mathbf{1 0 : 0 0}$ & 0,02 & 0,15 \\
& $\mathbf{1 2 : 0 0}$ & 0,03 & 0,4 \\
& $\mathbf{1 4 : 0 0}$ & 0,11 & 0,2 \\
& $\mathbf{1 5 : 0 0}$ & 0,03 & - \\
& $\mathbf{1 6 : 0 0}$ & 5,83 & 10,8 \\
& $\mathbf{1 7 : 0 0}$ & 0,1 & - \\
& $\mathbf{1 8 : 0 0}$ & 1,2 & 5,9 \\
& $\mathbf{2 0 : 0 0}$ & 5,4 & 0.2 \\
& $\mathbf{2 1 : 0 0}$ & 0,2 & 3,85 \\
Subtotal & $\mathbf{2 2 : 0 0}$ & 0,1 & 0,2 \\
\hline Monoinsaturados & $\mathbf{1 6 : 0 1}$ & 0,1 & 0.95 \\
& $\mathbf{2 4 : 0}$ & 0,8 & 1,4 \\
& & 13,82 & 1,75 \\
Subtotal & $\mathbf{2 4 : 0 1}$ & 0,05 & 0,1 \\
\hline poli-insaturados & $\mathbf{1 5 : 1 n 5}$ & 0,03 & 1,85 \\
\hline & & 0,18 & 1 \\
& & & \\
& & 1,01 & 22,65 \\
\hline
\end{tabular}

\begin{tabular}{lccc} 
& $\mathbf{1 8 : 1 n 9}$ & 69,5 & 61,7 \\
& $\mathbf{1 8 : 2 n 6}$ & 0,04 & 0,2 \\
& $\mathbf{1 8 : 3 n 6}$ & 0,1 & 0,2 \\
& $\mathbf{2 0 : 3 n 3}$ & 0.1 & 0,25 \\
& $\mathbf{2 0 : 3 n 6}$ & 0,1 & - \\
& $\mathbf{2 0 : 5 n 3}$ & 0,25 & 3,4 \\
& $\mathbf{2 2 : 0 2}$ & - & 0,15 \\
Subtotal & & 71,1 & 66,9 \\
\hline Não identificados & & 14,4 & 8,6 \\
& total & 100 & 100 \\
Lipídeos totais & & $16,4 \%$ & $6,20 \%$ \\
\hline
\end{tabular}

Fonte (autor)

O responsável por tal aumento foi C18:1n9 (ácido oléico) apresentando 69.5\% na amostra de $C$. vulgaris contra $61.7 \%$ na amostra de A. flos-aquae. Estes resultados vão de encontro com os reportados por Silva et al. (2010) em que caracteriza-se o óleo extraído de Moringa oleifera e observa-se a presença de $78 \%$ de ácido oléico. Rashid et al (2008) também apresentou mais que $70 \%$ de ácido oléico em suas amostras de Moringa. Segundo ele, algumas oscilações nos valores dos ácidos graxos podem ocorrer relacionadas com as variações das condições utilizadas pelo agricultor, tais como adubo, solo e a variedade da semente.

Segundo Qu et al. (2012), óleos com elevados valores de ácido oléico (>70\%) melhoram as propriedades do biodiesel, tais como, fluxo a frio, ponto de nuvem e ponto de fluidez, desta forma, o lodo produzido após tratamento com a dosagem ótima de Moringa oleifera, apresentou elevados valores de ácido oléico em sua composição, dados que tornam interessante a utilização desse resíduo à uma futura produção de biodiesel.

\section{CONCLUSÕES}

Verificou-se que a morfologia das microalgas altera a dosagem de Moringa oleifera requerida para a remoção dos parâmetros cor, turbidez, clorofila-a e compostos de absorção em $U_{254 n m}$, sendo que para a espécie filamentosa de Anabaena flos-aquae foi 
necessário $0,1 \quad$ g.L $\mathrm{L}^{-1}$, e para a espécie unicelular de Chlorella vulgaris foi necessário a concentração de 0,4 g. $\mathrm{L}^{-1}$.

Pode-se concluir também que a Moringa oleifera apresenta uma tendência de aumentar a quantidade de matéria orgânica na água tratada, visualizada através de análises de $\mathrm{UV}_{254 \mathrm{~nm}}$ pré e pós tratamento.

Com relação a caracterização lipídica do lodo gerado pelo processo, observou-se que após o tratamento com Moringa houve um aumento na quantidade desses lipídeos em ambas as espécies, evidenciando altos valores de ácido oléico, que é um precursor favorável para a obtenção de um biodiesel de qualidade.

\section{REFERÊNCIAS}

ABNT NBR 10004. Associacao Brasileira de Normas Tecnicas. Resíduos ólidos - Classificação 2a Ed. 2004.

AMARAL, P. A. P., CORAL, L. A., Nagel-Hassemer MA, Belli TJ, Lapolli FR. Association of dissolved air flotation (DAF) with microfiltration for cyanobacterial removal in water supply. Desalin Water Treat., v.51, p.1664-1671, 2013.

ARAÚJO, S. C. e GARCIA, V. M. T., "Growth and biochemical composition of the diatom Chaetoceros cf. wighamiibrightwell under different temperature, salinity and carbon dioxide levels. Protein, carbohydrates and lipids", Aquaculture, v. 246, p. 405-412, 2005.

BLIGH, E. G.; DYER, W. J., "A rapid method for total lipid extraction and purification". Can. J. Biochem. Physiol, v. 37, p. 911-917, 1959.

CAMACHO, F. P.; BONGIOVANI, M. C.; ARAKAWA, F. S.; SHIMABUKU, Q. L.; VIEIRA, A. M. S.; BERGAMASCO, R., "Advanced Processes of Cyanobacteria and Cyanotoxins Removal in Supply Water Treatment", Chemical Engineering Transactions, v. 32, p. 421-426, 2013.
COLLA, L. M.; BERTOLIN, T. E.; COSTA, J. A. V., "Fatty acids profile of Spirulina platensis grown under different temperatures and nitrogen concentrations". Zeitschrift für Naturforschung, v. 59, p.55-59, 2004.

FERNANDEZ, F. G. A.; PEREZ, J. A. S.; SEVILLA, J. M. F.; CAMACHO, F. G.; GRIMA, E. M., "Modeling of eicosapentaenoic acid (EPA) production from Phaeodactylum tricornutum cultures in tubular photobioreactors: Effects of dilution rate, tube diameter, and solar irradiance", Biotechnology and

Bioengineering, v. 68, p. 173-183, 2000. GOLTERMAN, H. L.; CLYMO, R. S.; OHNSTAND, M. A., "Methods for physical and chemical analysis of fresh water". Oxford: Blackwell, 213 p., 1978.

NICHOLS, B. W.; WOOD, B. J. "The occurrence and biosynthesis of gammalinolenic acid in a blue-green alga, Spirulina platensis".,Lipids, v. 3, n. 1, p. 46-50, 1968.

NISHI, L., GUILHERME, A. L. F., VIEIRA, A. M. S., de ARAUJO, A. A., AMBROSIO-UGRIi, M. C. B., BERGAMASCO, R., "Cyanobacteria removal by coagulation/flocculation with seeds of the natural coagulant Moringa oleifera Lam", Chemical Engineering Transactions, v. 24, p. 1129-1134, 2011.

NKURUNZIZA， T.; NDUWAYEZU, J.B., BANADDA, E.N.; NHAPI, I., "The effect of turbidity levels and Moringa oleifera concentration on the effectiveness of coagulation in water treatment", Water Science and Technology, v. 58, n.8, p. 15511558, 2009.

NWAIWU N. E.; LINGMU, B., "Studies on the effect of settling time on coliform reduction using Moringa oleifera seed powder". Journal of Applied Sciences in Environmental Sanitation, v. 6, n. 3, p. 279-286, 2011. 
QU, J.; MAO, H.; CHEN, W.; GAO, S.; BAI, Y.; SUN, Y.; GENG, Y.; YE, J., "Development of marker-free transgenic Jatropha plants with increased levels of seed oleic acid", Biotechnology for Biofuels, v. 5, n. 10, p. 1-10, 2012.

RASHID, U.; ANWAR, F.; MOSER, B. R.; KNOTHE, G., "Moringa oleifera oil: A possible source of biodiesel", Bioresource technology, v. 99, n.17, p. 8175-8179, 2008.

RENAUD, S. M.; THINH, L. V.; LAMBRINIDIS, G.; PARRY, D. L., "Effect of temperature on growth,chemical composition and fatty acid composition of tropical Australian microalgae grown in batch cultures". Aquaculture, v. 211, p. 195-214, 2002.

SILVA, M. O., "Caracterização física e química da semente de Moringa oleifera e estudo do processo de obtenção do óleo". Dissertação. (Mestrado em Ciência de Alimentos). Universidade Estadual de Maringá, Maringá-PR, 2013.

SILVA, J. P. V., SERRA, T. M., GOSMANN, M., WOLF, C. R., MENEGHETTI, M. R., MENEGHETTI, S. M. P. Moringa oleífera oil: studies of characterization and biodiesel production. Biomass and Bioenergy. v. 34, p. 1527-1530. 2010.

TEIXEIRA, C. M. L. L., KIRSTEN, F. V., TEIXEIRA, P. C. N., "Evaluation of Moringa oleifera seed flour as a flocculating agent for potential biodiesel producer microalgae", J Appl Phycol., n. 24, p. 557563, 2012.

TEIXEIRA, M. R., ROSA, M. J. Comparing dissolved air flotation and conventional sedimentation to remove cyanobacterial cells of Microcystis aeruginosa: Part II. The effect of water background organics. Sep Purif Technol., v.53, p.126-134, 2007. 